Article

\title{
Prediction of Degreening Velocity of Broccoli Buds Using Hyperspectral Camera Combined with Artificial Neural Networks
}

\author{
Yoshio Makino *(D) and Yumi Kousaka \\ Graduate School of Agricultural and Life Sciences, The University of Tokyo, 1-1-1, Yayoi, Bunkyo-ku, \\ Tokyo 113-8657, Japan; yumi.kousaka@gmail.com \\ * Correspondence: amakino@mail.ecc.u-tokyo.ac.jp; Tel.: +81-(3)-5841-5361
}

Received: 14 March 2020; Accepted: 23 April 2020; Published: 2 May 2020

\begin{abstract}
Developing a noninvasive technique to estimate the degreening (loss of green color) velocity of harvested broccoli was attempted. Loss of green color on a harvested broccoli head occurs heterogeneously. Therefore, hyperspectral imaging technique that stores spectral reflectance with spatial information was used in the present research. Using artificial neural networks (ANNs), we demonstrated that the reduction velocity of chlorophyll at a site on a broccoli head was related to the second derivative of spectral reflectance data at 15 wavelengths from 405 to $960 \mathrm{~nm}$. The reduction velocity was predicted using the ANNs model with a correlative coefficient of 0.995 and a standard error of prediction of $5.37 \times 10^{-5} \mathrm{mg} \cdot \mathrm{g}^{-1} \cdot \mathrm{d}^{-1}$. The estimated reduction velocity was effective for predicting the chlorophyll concentration of broccoli buds until $7 \mathrm{~d}$ of storage, which was established as the maximum time for maintaining marketability. This technique may be useful for nondestructive prediction of the shelf life of broccoli heads.
\end{abstract}

Keywords: Brassica oleracea var. italica; chlorophyll; mathematical model; nondestructive analysis; shelf life; spectroscopy; statistical analysis; vegetable

\section{Introduction}

Broccoli (Brassica oleracea var. italica) is one of the main vegetables with $26.5 \mathrm{Mt}$ of the commodity harvested in 2018 in the world (FAOSTAT, broccoli + cauliflower [Brassica oleracea var. botrytis]) [1]. Since the early 1980s, broccoli has been reported as a food to depress cancer [2] since it includes sulforaphane [3,4], which is useful for depressing the growth of Helicobacter pylori, the main reason for gastric cancer [5]. However, loss of green color (degreening) is the main phenomenon that decreases the shelf life of harvested broccoli [6] and is induced by the reduction of pigment (chlorophyll) [7]. Loss of green color may cause a reduction of effects suitable for health-promotion by broccoli since chlorophyll is useful for reducing serum cholesterol in mammals [8,9]. Lipton \& Harris [10] subjectively evaluated the appearance of broccoli heads by scales (nine levels), while Jacobssonet al. [11] chose a visual technique to assess the appearance of broccoli and determined a threshold that $30 \%$ of the buds had turned yellow. Objective measurement of the appearance of broccoli heads has also been conducted. Shewfelt et al. [6] noninvasively evaluated the appearance of six cultivars of harvested broccoli by two types of colorimeters. Ren et al. [12] proposed models for evaluating changes in broccoli color on the basis of values measured using a colorimeter, though Kasim et al. [13] measured the hue angle using a colorimeter to assess the color of broccoli packaged in several kinds of film pouches after use of 1-methylcyclopropene (1-MCP). However, Lipton \& Harris [10] published that localization of degreening (loss of green color) was observed. This report indicated that it is difficult to select a colorimeter (point-based method) to measure loss of green color at local sites. In contrast, 
hyperspectral camera has been utilized in studies to measure pigment concentrations in forests as a tool for remote sensing [14]. This method has been used as a technique for evaluating food safety and quality control [15]. Hyperspectral imaging (spatial spectral reflectance data) was utilized by Qin et al. [16] to find citrus cankers and Ariana \& $\mathrm{Lu}[17,18]$ to find internal defects and the appearance of whole pickles and cucumbers (Cucumis sativus L.). Ahn et al. [19] measured nutrient contents in some kinds of food products using hyperspectral signals based on deep neural networks. Feng et al. [20] evaluated the hygiene of sausage by measuring the spatial distribution of adenosine $5^{\prime}$-triphosphate using hyperspectral camera. Applications of a hyperspectral imaging camera for inspecting food quality and safety have been reported day by day. These studies indicated that hyperspectral imaging may be useful for finding loss of green color on broccoli heads because it provides both spectral and spatial data. For example, the chlorophyll content at leaf and canopy levels in forests was assumed by hyperspectral imaging as a remote sensing technique [21,22]. Xue and Yang [23] measured chlorophyll content in some kinds of leafy vegetables using hyperspectral camera. Kabakeriset al. [24] evaluated quality loss of broccoli by hyperspectral imaging.

In the current study, we tried to estimate the velocity of loss of green color of harvested broccoli by a more advanced method than that used in previous researches. Estimation of the velocity of loss of green color at random locations at the initiation of storage or transportation permits the grading of products according to their shelf lives. This grading is effective for determining the order of shipment and distribution as raw or frozen products. This method is effective for reduction of waste as well. According to the report [25], 34\% of fruits and vegetables produced were wasted without consumption in the world. Reduction of the waste using the proposed grading method is equivalent to the increase of production. Near-infrared spectroscopy combined with artificial neural networks (ANNs) is useful for estimating the content of components in horticultural commodities [26]. The effectiveness of ANNs in food analysis has also been reported [27].

The objective of this research was to propose a technique for estimating the velocity of loss of green the color of harvested broccoli by ANNs and spectral reflectance on the basis of hyperspectral images.

\section{Materials and Methods}

\subsection{Samples and Preparation}

Heads of broccoli (Sakata Seed Corporation, cv. SK048) were harvested 1 day before experiments at a farmland in Fukaya (N: 36.209749, E: 139.215149, Saitama Pref., Japan). After harvest, the samples in cardboard boxes were carried to the laboratory at $5{ }^{\circ} \mathrm{C}$ within $24 \mathrm{~h}$. Seventeen broccoli heads were selected as samples and the size of samples (height) were adjusted to $130 \mathrm{~mm}$ by trimming the main stems of the heads so that the aperture between the heads and the illumination rod remained constant. The samples were wrapped in macro-perforated low-density polyethylene pouches (eight perforations per pouch; diameter, $6 \mathrm{~mm}$; thickness, $25 \mu \mathrm{m}$ ) and stored in a chamber at $5{ }^{\circ} \mathrm{C}$ and $70 \%$ relative humidity for the following experiments.

\subsection{Determination of Spectral Data by the Hyperspectral Camera System}

The overall view and description of the parts of the hyperspectral camera system (JFE Techno-Research Corporation, Tokyo, Japan) are presented in Figure 1, the same as the previous report [28]. 


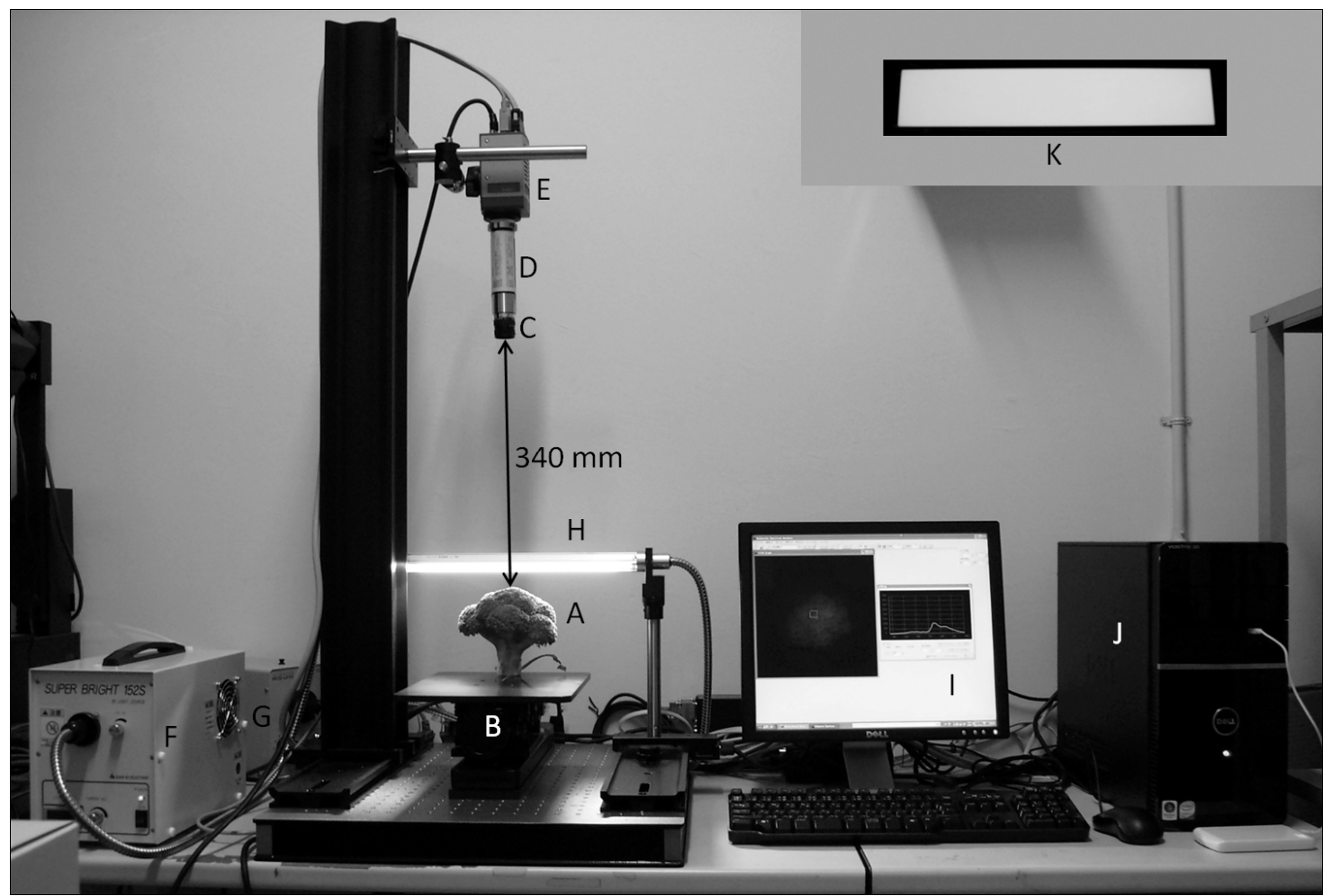

Figure 1. Overall view and description of the components in the hyperspectral camera system (JFE Techno-Research Corporation, Tokyo, Japan) [28]. A, Sample; B, Sample stage; C, Lens; D, Spectrograph; E, 12 bit CCD camera; F, 150 W Xe lamp; G, $150 \mathrm{~W}$ tungsten halogen lamp; H, $250 \mathrm{~mm}$ illumination rod; I, 17 inch monitor; J, desktop computer; $\mathrm{K}, 40 \mathrm{~mm} \times 220 \mathrm{~mm}$ white reference.

The prepared broccoli samples were stored at $5{ }^{\circ} \mathrm{C}$ in a chamber for $48 \mathrm{~d}$. The spectral reflectance of the samples was determined by the system over the wavelength in the range of $380-1000 \mathrm{~nm}$, wavelength resolution of $5 \mathrm{~nm}$, and driving velocity of the stage of $0.41 \mathrm{~mm} \cdot \mathrm{s}^{-1}$. Intensity of light reflectance from a sample was transformed by recording the dark current image to 0 and from white standard image to 1. A SpectrumAnalyzer ${ }^{\circledR}$ ver. 1.8.6 (JFE Techno-Research Corporation, Tokyo, Japan) was utilized for getting and analyzing the "hyper-cube data" [15] acquired using the system. Then it was assumed that the curvature effect on the broccoli head was too small to be ignored in the present study. The mass of each sample was determined during storage as well as the spectral reflectance.

\subsection{Destructive Measurement of Chlorophyll Content in Broccoli}

Pigment contents were related to reflectance values referred to the publication by Nicotra et al. [22]. The spectral reflectance of a broccoli head was measured before and after the following sampling treatments. Broccoli buds were sampled from around the center of the head and stored at $-80{ }^{\circ} \mathrm{C}$ until use. The spectral reflectance at the sampling sites on the buds was determined by comparing the reflectance before and after the sampling. The hue angle $\left(\tan ^{-1}\left(b^{*} / a^{*}\right)\right)$ was determined from the spectral reflectance that ranged from 380 to $780 \mathrm{~nm}$ by the method of the Commission International de l'Eclairage (CIE). The chlorophyll content $\left(\mathrm{mg} \cdot \mathrm{g}^{-1}\right.$ ) was determined by measuring $80 \%$ acetone solution including chlorophyll prepared from bud samples using a UV-3600 spectrophotometer (Shimadzu Corporation, Kyoto, Japan) [29]. An equation to relate $C$ to $H^{\circ}$ was proposed by simple regression analysis reported by Ren et al. [12]. 


\subsection{Constraction of a Model to Predict the Velocity of Chlorophyll Reduction}

Ten arbitrary $6 \mathrm{~mm} \times 6 \mathrm{~mm}$ regions of interest (ROIs) were chosen from a broccoli head and the mean values of spectral reflectance of these ROIs was determined (spatial resolution: $0.00281 \mathrm{~mm}^{2}$ per pixel). The mean value at the same ROIs chosen above were collected from the start $(0 \mathrm{~d})$ to the end of storage (48 d). Eleven heads (110 ROIs) and six heads (60 ROIs) were used for the calibration and validation sets.

The chlorophyll contents were drawn in a scatter graph, and the changes over time were fitted using straight lines. According to the experimental data, the degradation velocity of chlorophyll during storage was presumed to be constant in the study. The degradation velocity can be expressed as follows:

$$
C_{t}=C_{0}+k t
$$

The value of parameter $k$ should be predicted from spectral reflectance at the start of storage. Then, the degreening velocity of broccoli buds during storage can be predicted using nondestructive analysis.

Calculations in this research were conducted using JMP ${ }^{\circledR}$ 8.0.2 (SAS Institute Inc., Cary, NC, USA), with the exception of the second derivative of spectral reflectance $\left(\delta^{2} R\right)$, which was calculated using Origin ${ }^{\circledR}$ 7.5J (Lightstone Co., Tokyo, Japan). The wavelengths needed for construction of the equations were chosen by linear correlative coefficients between the second derivative of spectral reflectance $\left(\delta^{2} R\right)$ as the independent variables and $k$ as an exemplar at each wavelength, using the 110 samples chosen for calibration. The linear correlative coefficient was determined as follows:

Equations were made using ANNs and the calibration values. The $\delta^{2} R$ values at some wavelengths were chosen as independent variables for ANN modeling.

ANNs use a non-linear fitting way and are considered to be useful for complicated objects such as biological organizations. JMP software applies plural approximation methods, such as the Gauss-Newton way, a type of logistic curve, as the activating function for ANNs. The ANNs contained an input layer, a hidden layer of neurons, and an output layer.

$$
\begin{gathered}
X_{i h}=A_{h}+\sum[j=1, m] B_{j h} \cdot d_{i j}, \\
H_{i h}=1 /\left[1+\exp \left(-X_{i h}\right)\right], \\
\hat{k}_{i}=C+\sum[h=1, l] D_{h} \cdot H_{i h}
\end{gathered}
$$

ANNs were conducted under the conditions as follows: the number of layers, 3 ; number of hidden nodes, 3; number of repeated calculations, 75 ; over fit penalty, 0.01 ; number of calculations, 1 ; standard of convergence, 0.5 ; and random number seed 274510453 . ANN calculation can be reproduced under the conditions mentioned above.

\subsection{Precision of a Proposed Equation}

To calibrate the method, the standard error of calibration (SEC) and correlative coefficient of calibration were calculated using Equation (5), and used as indices to evaluate the fit of the proposed equation to the actual values.

$$
\mathrm{SEC}=\left[\left\{\sum[i=1, n]\left(k_{i}-\hat{k}_{i}\right)^{2}\right\} /(n-j-1)\right]^{0.5},
$$

Data of $\delta^{2} R$ for 60 samples at the 15 chosen wavelengths were utilized as the input data for validating the calibrated ANNs. Standard error of prediction (SEP) and bias, used as indicators for testing the approximation of a proposed equation to the actual values for validation, were checked using the predicted $\hat{k}$ values as output data:

$$
\bar{b}=(1 / n) \sum[i=1, n] b_{i},
$$




$$
\begin{gathered}
\left(b_{i}=k_{i}-\hat{k}_{i}\right), \\
\mathrm{SEP}=\left[\left\{\sum[i=1, n]\left(b_{i}-\bar{b}_{i}\right)^{2}\right\} /(n-1)\right]^{0.5},
\end{gathered}
$$

Bias is the mean difference between the predicted and actual values. The correlative coefficient of validation was determined by conventional methods from the validation data. SEP, the correlative coefficient of validation, was the index used for checking the approximation of a proposed equation to the measured values for validation.

\section{Results and Discussion}

The relationship between $H^{\circ}$ and chlorophyll concentration was approximated by the calibration line as shown in Figure 2. The observed minimum $H^{\circ}$ in the current study was 80.1. Therefore, the $C$ value was never a negative value.

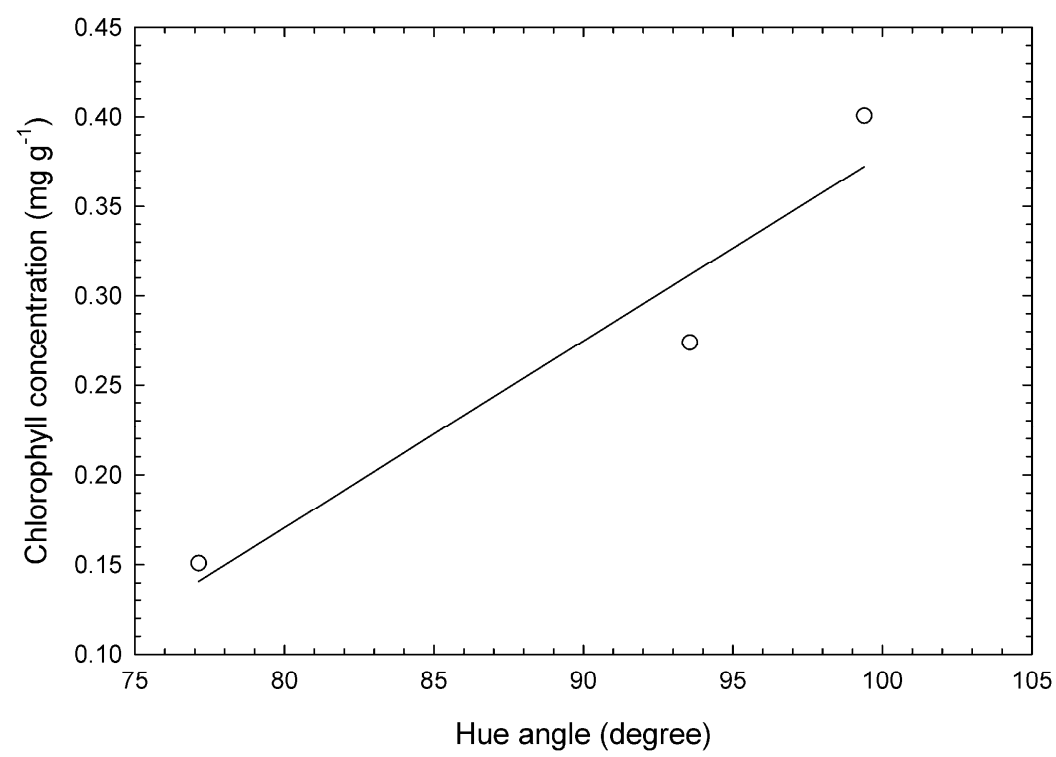

Figure 2. Relationship between hue angle and chlorophyll concentration in broccoli buds. The open circles and full line are the actual values and single regression line $\left(C=0.0104 H^{\circ}-0.6613\right)$. Bias was $2.12 \times 10^{-4} \mathrm{mg} \cdot \mathrm{g}^{-1}$, standard error of calibration $2.79 \times 10^{-2} \mathrm{mg} \cdot \mathrm{g}^{-1}$, relative percent difference 4.48, and correlative coefficient of validation 0.962 .

The chlorophyll concentration of the broccoli buds decreased linearly over time in the current study. Van Boekel [30] and Ren et al. [12] approximated the changes in chlorophyll concentrations using logarithmic functions. However, the degreening velocity was determined as the slope of the experimental data calculated by linear regression analysis using Equation (1). The velocity during storage was attempted to predict using hyperspectral images on the initial day of storage in the present study.

The raw and second derivatives of spectral reflectance in the range of 380 and $1000 \mathrm{~nm}$ from 11 broccoli heads (110 ROIs) are shown in Figure 3. This pretreatment was conducted to eliminate the influence of baseline on spectral reflectance [31]. The pretreated data was used for constructing an ANN calibration model. 


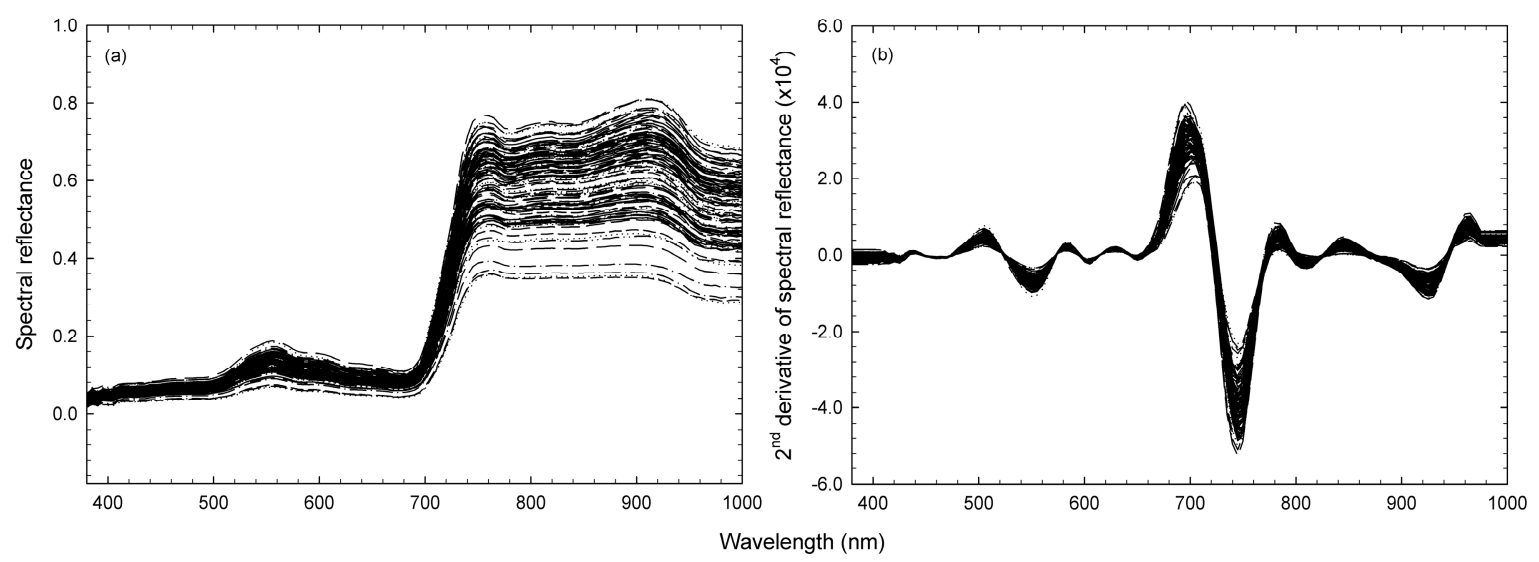

Figure 3. (a) Raw and (b) second derivatives of spectral reflectance in the range of 380 and $1000 \mathrm{~nm}$ from 11 broccoli heads (110 regions of interest).

The correlative coefficients at every wavelength between $k$ and $\delta^{2} R$ are shown in Figure 4 . Fifteen of the wavelengths with a high correlative coefficient (absolute value) and without multicollinearity were chosen (Figure 4 ). The $\delta^{2} R$ values at six wavelengths correlated negatively with the $k$ value, while the $\delta^{2} R$ values at nine wavelengths correlated positively with the $k$ value, and thus, were chosen as independent variables (Figure 4). Peiris et al. [32] predicted the total soluble solid (TSS) of tomatoes using the second derivative of spectral absorbance in the range of $780-980 \mathrm{~nm}$. Therefore, the range of absorption spectra in this research may be related to TSS, which is composed mainly of sucrose, fructose, and glucose. These sugars stimulate metabolic activity because they are associated with glycolysis, which contributes to the generation of adenosine $5^{\prime}$-triphosphate needed for many biological reactions. Therefore, reflectance may be associated with the $k$ value that represents the degradation velocity of chlorophyll. According to the Merck Index [33], reflectance between 405 and $670 \mathrm{~nm}$ may be associated with chlorophyll $a$ and $b$. However, the correlative coefficients between reflectance values at selected wavelengths and $k$ values were not as high. This suggests that chlorophyll concentration at the start of storage did not affect the deterioration velocity of chlorophyll. Loss of the green color is due to the transformation of pheide $a$ to the primary fluorescent chlorophyll catabolite. Aiamla-or et al. [7] reported that chlorophyll-degrading peroxidase 3 was responsible for chlorophyll degradation in postharvest broccoli florets. Although there are data for the spectral absorbance of the enzyme cytochrome $c$ oxidase $[34,35]$, we have not found any report on enzymes responsible for the degreening of plants. Although absorbance at $280 \mathrm{~nm}$ is used frequently to quantify proteins [36], it is difficult to detect the target enzymes amongst all the proteins. Therefore, spectral reflectance may not directly relate to the velocity of loss of the green color and needs to be tested by statistical methods.

The statistics of the calibration and validation data sets are shown in Table 1. The relationship between measured $k$ and estimated $\hat{k}$ using ANNs as a measure of validation is shown in Figure 4 . The approximation between the values of the proposed equation and the unknown measured values was better with a high correlative coefficient and a low SEP. According to the results from multiple linear regression analysis, bias was $0.377 \mathrm{mg} \cdot \mathrm{g}^{-1} \cdot \mathrm{d}^{-1}$, SEP $6.65 \times 10^{-3} \mathrm{mg} \cdot \mathrm{g}^{-1} \cdot \mathrm{d}^{-1}$, and correlative coefficient of validation was 0.247 . According to the results from partial least square regression analysis, bias was $-1.15 \times 10^{-4} \mathrm{mg} \cdot \mathrm{g}^{-1} \cdot \mathrm{d}^{-1}$, SEP $4.48 \times 10^{-4} \mathrm{mg} \cdot \mathrm{g}^{-1} \cdot \mathrm{d}^{-1}$, and correlative coefficient of validation was 0.400 . Prediction results by these linear regression methods were worse than ANNs as a nonlinear method. Williams \& Norris [26] reported that a correlative coefficient over 0.99 could be used in any application. This indicates that ANNs using spectral reflectance from 405 to $960 \mathrm{~nm}$ could be utilized for predicting the velocity of chlorophyll reduction. According to the data range in Table 1 , ANNs cover the velocity of chlorophyll reduction, which ranged from $-3.39 \times 10^{-3}$ to $-1.05 \times 10^{-3} \mathrm{mg} \cdot \mathrm{g}^{-1} \cdot \mathrm{d}^{-1}$. Therefore, 59 actual data points in Figure 5, which ranged from $-3.00 \times 10^{-3}$ to $-1.21 \times 10^{-3} \mathrm{mg} \cdot \mathrm{g}^{-1} \cdot \mathrm{d}^{-1}$, 
were supported. Only an actual data as $-3.92 \times 10^{-3} \mathrm{mg} \cdot \mathrm{g}^{-1} \cdot \mathrm{d}^{-1}$ out of the supported range might be farther from the regression line than the other plots.

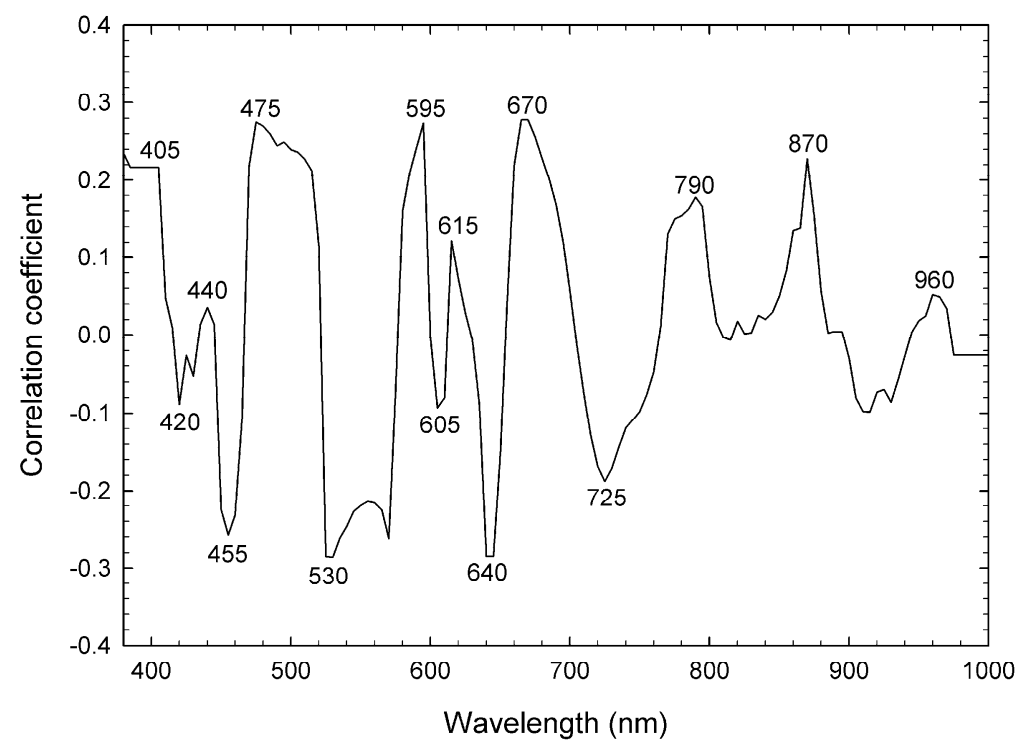

Figure 4. Correlative coefficients between the chlorophyll degradation velocity and reflectance at $5 \mathrm{~nm}$ wavelength bands between 380 and $1000 \mathrm{~nm}$.

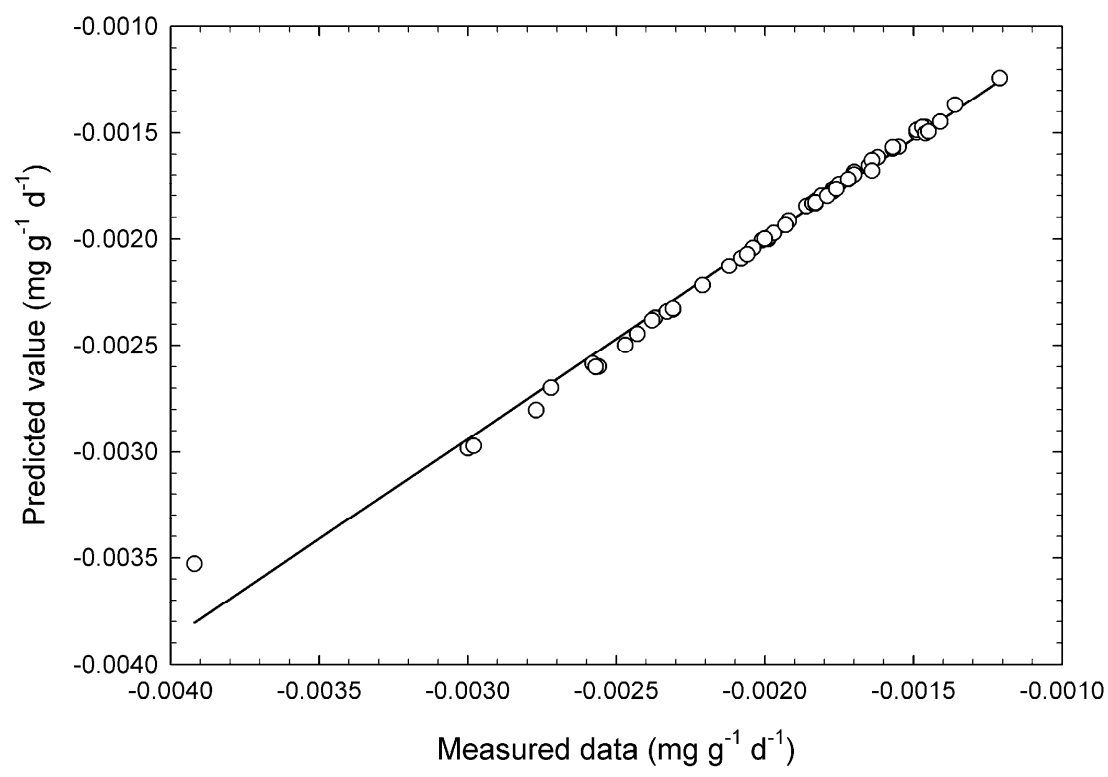

Figure 5. Validation for predicting the chlorophyll degradation velocity of broccoli heads at 60 regions of interest by artificial neural networks. The open circles and full line are the actual values and single regression line. Bias was $-4.82 \times 10^{-7} \mathrm{mg} \cdot \mathrm{g}^{-1} \cdot \mathrm{d}^{-1}$, standard error of prediction $5.37 \times 10^{-5} \mathrm{mg} \cdot \mathrm{g}^{-1} \cdot \mathrm{d}^{-1}$, and correlative coefficient of validation was 0.995 . This level of correlation was significant at the $99.9 \%$ level calculated using the F-test. 
Table 1. Statistics of exemplar (chlorophyll degradation velocity of broccoli buds) and independent variables (second derivative of absorbance at chosen wavelengths) within calibration and validation sets.

\begin{tabular}{|c|c|c|c|c|c|c|}
\hline \multirow{2}{*}{ Exemplar or Variables } & \multicolumn{3}{|c|}{ Calibration Set $(n=110)$} & \multicolumn{3}{|c|}{ Validation Set $(n=60)$} \\
\hline & Range & Mean & $\mathrm{SD}^{1}$ & Range & Mean & $\mathrm{SD}^{1}$ \\
\hline $\begin{array}{l}\text { Chlorophyll degradation } \\
\text { velocity }\left(\mathrm{mg} \cdot \mathrm{g}^{-1} \cdot \mathrm{d}^{-1}\right)\end{array}$ & $-3.39 \times 10^{-3}-\left(-1.05 \times 10^{-3}\right)$ & $1.97 \times 10^{-3}$ & $4.88 \times 10^{-4}$ & $-3.92 \times 10^{-3}-\left(-1.21 \times 10^{-3}\right)$ & $1.97 \times 10^{-3}$ & $4.83 \times 10^{-4}$ \\
\hline $405 \mathrm{~nm}$ & $-2.50 \times 10^{-5}-1.48 \times 10^{-5}$ & $-6.60 \times 10^{-6}$ & $8.38 \times 10^{-6}$ & $-3.80 \times 10^{-5}-7.73 \times 10^{-6}$ & $-1.20 \times 10^{-5}$ & $8.95 \times 10^{-6}$ \\
\hline $420 \mathrm{~nm}$ & $-1.70 \times 10^{-5}-5.72 \times 10^{-6}$ & $-8.40 \times 10^{-6}$ & $5.09 \times 10^{-6}$ & $-1.80 \times 10^{-5}-3.83 \times 10^{-6}$ & $-7.90 \times 10^{-6}$ & $5.21 \times 10^{-6}$ \\
\hline $440 \mathrm{~nm}$ & $3.76 \times 10^{-6}-1.19 \times 10^{-5}$ & $7.13 \times 10^{-6}$ & $1.69 \times 10^{-6}$ & $3.70 \times 10^{-6}-1.25 \times 10^{-5}$ & $7.78 \times 10^{-6}$ & $1.87 \times 10^{-6}$ \\
\hline $455 \mathrm{~nm}$ & $-6.90 \times 10^{-6}-\left(-2.90 \times 10^{-6}\right)$ & $-4.70 \times 10^{-6}$ & $8.17 \times 10^{-7}$ & $-6.30 \times 10^{-6}-\left(-3.10 \times 10^{-6}\right)$ & $-4.80 \times 10^{-6}$ & $7.58 \times 10^{-7}$ \\
\hline $475 \mathrm{~nm}$ & $-3.10 \times 10^{-6}-4.65 \times 10^{-6}$ & $-5.30 \times 10^{-7}$ & $1.45 \times 10^{-6}$ & $-3.20 \times 10^{-6}-4.71 \times 10^{-6}$ & $-8.30 \times 10^{-7}$ & $1.50 \times 10^{-6}$ \\
\hline $530 \mathrm{~nm}$ & $-3.80 \times 10^{-5}-\left(-7.40 \times 10^{-6}\right)$ & $-1.90 \times 10^{-5}$ & $5.54 \times 10^{-6}$ & $-4.10 \times 10^{-5}-\left(-8.60 \times 10^{-6}\right)$ & $-1.80 \times 10^{-5}$ & $5.60 \times 10^{-6}$ \\
\hline $595 \mathrm{~nm}$ & $-2.70 \times 10^{-6}-6.40 \times 10^{-6}$ & $4.61 \times 10^{-7}$ & $1.76 \times 10^{-6}$ & $-2.00 \times 10^{-6}-5.80 \times 10^{-6}$ & $8.28 \times 10^{-7}$ & $1.66 \times 10^{-6}$ \\
\hline $605 \mathrm{~nm}$ & $-2.40 \times 10^{-5}-\left(-9.30 \times 10^{-6}\right)$ & $-1.6 \times 10^{-5}$ & $2.64 \times 10^{-6}$ & $-2.00 \times 10^{-5}-\left(-9.50 \times 10^{-6}\right)$ & $-1.6 \times 10^{-5}$ & $2.64 \times 10^{-6}$ \\
\hline $615 \mathrm{~nm}$ & $-3.30 \times 10^{-7}-2.46 \times 10^{-6}$ & $1.14 \times 10^{-6}$ & $6.51 \times 10^{-7}$ & $-5.70 \times 10^{-7}-2.76 \times 10^{-6}$ & $1.19 \times 10^{-6}$ & $6.71 \times 10^{-7}$ \\
\hline $640 \mathrm{~nm}$ & $2.40 \times 10^{-6}-9.81 \times 10^{-6}$ & $6.24 \times 10^{-6}$ & $1.42 \times 10^{-6}$ & $2.39 \times 10^{-6}-9.22 \times 10^{-6}$ & $6.63 \times 10^{-6}$ & $1.46 \times 10^{-6}$ \\
\hline $670 \mathrm{~nm}$ & $1.95 \times 10^{-5}-9.14 \times 10^{-5}$ & $4.74 \times 10^{-5}$ & $1.32 \times 10^{-5}$ & $2.10 \times 10^{-5}-1.01 \times 10^{-4}$ & $4.57 \times 10^{-5}$ & $1.41 \times 10^{-5}$ \\
\hline $725 \mathrm{~nm}$ & $-1.20 \times 10^{-4}-2.28 \times 10^{-5}$ & $-4.40 \times 10^{-5}$ & $2.90 \times 10^{-5}$ & $-1.40 \times 10^{-4}-1.66 \times 10^{-6}$ & $-4.80 \times 10^{-5}$ & $3.12 \times 10^{-5}$ \\
\hline $790 \mathrm{~nm}$ & $3.68 \times 10^{-6}-6.55 \times 10^{-5}$ & $3.67 \times 10^{-5}$ & $1.55 \times 10^{-5}$ & $1.14 \times 10^{-5}-7.99 \times 10^{-5}$ & $3.91 \times 10^{-5}$ & $1.54 \times 10^{-5}$ \\
\hline $870 \mathrm{~nm}$ & $-8.90 \times 10^{-6}-7.72 \times 10^{-6}$ & $4.00 \times 10^{-7}$ & $3.53 \times 10^{-6}$ & $-5.90 \times 10^{-6}-7.42 \times 10^{-6}$ & $3.23 \times 10^{-7}$ & $3.23 \times 10^{-6}$ \\
\hline $960 \mathrm{~nm}$ & $3.61 \times 10^{-5}-1.07 \times 10^{-4}$ & $7.14 \times 10^{-5}$ & $1.51 \times 10^{-5}$ & $2.79 \times 10^{-5}-1.02 \times 10^{-4}$ & $6.97 \times 10^{-5}$ & $1.85 \times 10^{-5}$ \\
\hline
\end{tabular}

${ }^{1}$ SD: standard deviation. 
According to previous reports [37], the $k$ values were calculated using a wide range of chlorophyll concentrations, which generated approximated lines or calibration lines using a wide range of data. Although a completely degreened broccoli head is considered to lose its merchantability, there are no reports on the relationship between loss of green color and marketability of the vegetable. Kasim et al. [13] described that a mass loss of $10 \%$ makes horticultural products unusable. The changes in mass loss of broccoli heads used for validation are shown in Figure 6. This data shows that mean mass loss exceeded $10 \%$ after $7 \mathrm{~d}$ of storage and reached $43 \%$ at the end of storage. Therefore, the ANN model practically supports the chlorophyll degradation velocity until $7 \mathrm{~d}$. The relationship between measured and predicted chlorophyll concentrations of broccoli buds on day 3 demonstrated that the heads remained fresh and on day 7 had just before lost about $10 \%$ of their mass (Figure 7 ). The predicted values were calculated using $\hat{k}$ values estimated by the constructed ANN model. This may be the reason behind SEP for chlorophyll concentrations being higher than the $\hat{k}$ values. Plots for day 7 tended to shift to the lower left of the figure compared with those for day 3 , which is due to the loss of chlorophyll over time. There was a positive correlation between the measured and predicted concentrations. According to the values of the correlative coefficients, this prediction level was effective for rough screening [26]. The proposed ANN model was effective in predicting chlorophyll concentration during storage using the predicted degreening velocity $\hat{k}$.

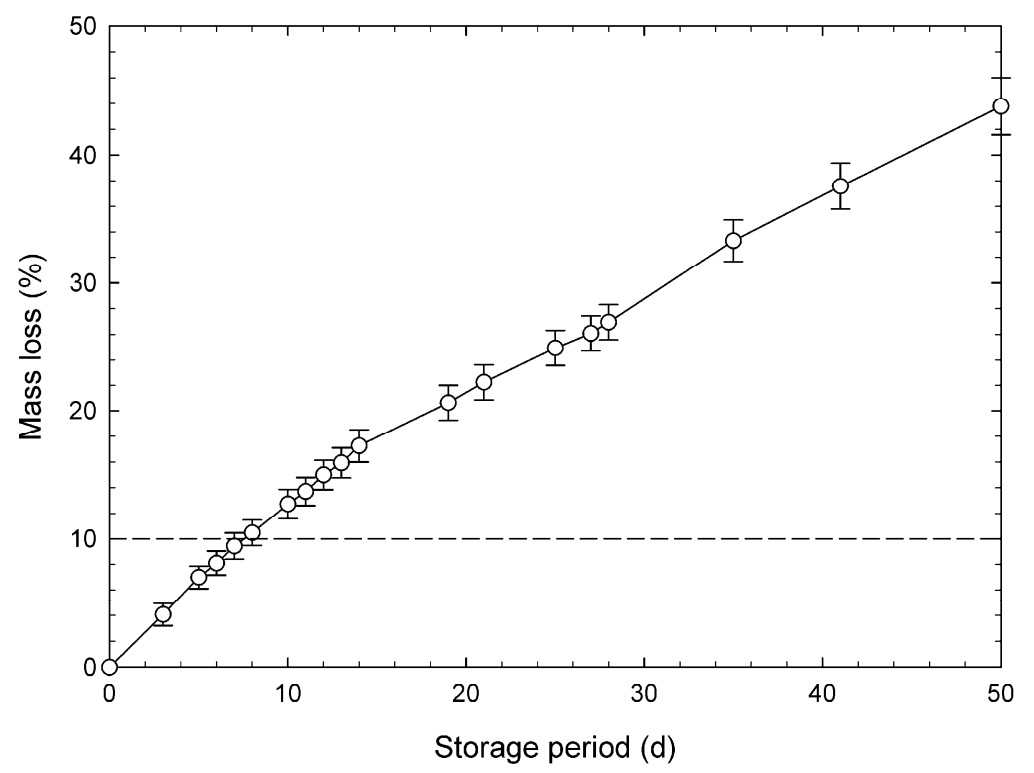

Figure 6. Change in mass loss of broccoli heads. The mean \pm SE of six observations has been plotted.

Reflectance or absorption spectra combined with statistical methods have been used to predict many kinds of characteristics of horticultural products such as TSS, moisture, and hardness [32], and multiple regression analyses or partial least square regression analyses have been adopted as statistical methods [37]. Such linear methods can be adopted to predict contents with a relatively high concentration. However, other methods need to be considered for estimating contents that are difficult to predict using linear methods. ANNs combined with spectral data were evaluated as a potential statistical method [26]. Peiris et al. [32] estimated SSC in apples (Malus pumila Mill.), while Makino et al. [38] estimated $\mathrm{O}_{2}$ uptake rate of tomatoes (Solanum lycopersicum L.). Siripatrawan et al. [39] determined the type and cell number of Escherichia coli (Migula) in liquid media and spinach. In the current study, we nondestructively predicted the degreening velocity of broccoli for the first time. 


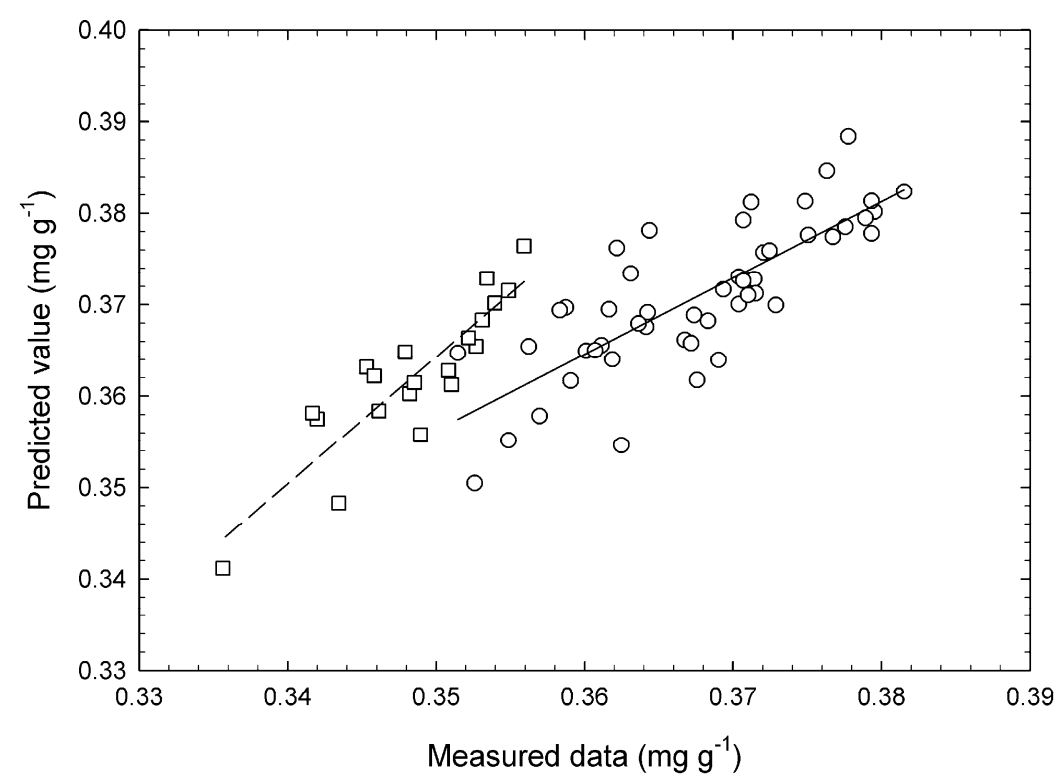

Figure 7. Relationship between measured and predicted chlorophyll concentrations after 3 and $7 \mathrm{~d}$ of storage. The circles and squares denote the plots for days 3 and 7 , respectively. The solid lines denote the linear regression lines for day 3 (Bias $3.31 \times 10^{-3} \mathrm{mg} \cdot \mathrm{g}^{-1}$, standard error of prediction $5.03 \times 10^{-3} \mathrm{mg} \cdot \mathrm{g}^{-1} \cdot \mathrm{d}^{-1}$, correlative coefficient of validation 0.795 ; significant at the $99.9 \%$ level calculated using the $F$-test). The dashed lines denote the linear regression lines for day 7 (Bias $1.37 \times 10^{-2} \mathrm{mg}^{-1} \mathrm{~g}^{-1}$, standard error of prediction $4.33 \times 10^{-3} \mathrm{mg} \cdot \mathrm{g}^{-1} \cdot \mathrm{d}^{-1}$, correlative coefficient of validation 0.884 ; significant at the $99.9 \%$ level calculated using the $F$-test).

ANNs are useful for fitting to nonlinear relationships [26]. This indicates that there are nonlinear relationships between the velocity of loss of green color and reflectance of visible/near-infrared illumination. Because it is difficult to predict the contents of enzymes, which are directly controlling the chlorophyll degradation, the technique found in this research, a non-linear model combined with the determination of spectral reflectance, may be useful for predicting the velocity of loss of green color, thereby providing a nondestructive prediction of the deterioration velocity of broccoli florets.

Author Contributions: Conceptualization, Y.M.; methodology, Y.K.; software, Y.K.; validation, Y.M.; formal analysis, Y.K.; investigation, Y.K.; resources, Y.M.; data curation, Y.K.; writing-original draft preparation, Y.M.; writing—review and editing, Y.K.; visualization, Y.M.; supervision, Y.M.; project administration, Y.M.; funding acquisition, Y.M. All authors have read and agreed to the published version of the manuscript.

Funding: This research was funded by Japan Society for the Promotion of Science, Grant-in-Aid for Scientific Research (No. 21380155).

Conflicts of Interest: The authors declare no conflict of interest.

\section{Nomenclature}

$a^{*}$

color axis of the Commission International de l'Eclairage (CIE)

constant

deviation between individual and mean measured degradation velocity of chlorophyll

$\left(\mathrm{mg} \cdot \mathrm{g}^{-1} \cdot \mathrm{d}^{-1}\right)$

color axis defined by CIE

bias (mean of deviation $b$ )

weighted connection between input and hidden layers in an artificial neural networks

constant $\left(\mathrm{mg} \cdot \mathrm{g}^{-1} \cdot \mathrm{d}^{-1}\right)$

chlorophyll concentration $\left(\mathrm{mg} \cdot \mathrm{g}^{-1}\right)$

input data: $\delta^{2} R$ (2nd derivative of spectral reflectance) 


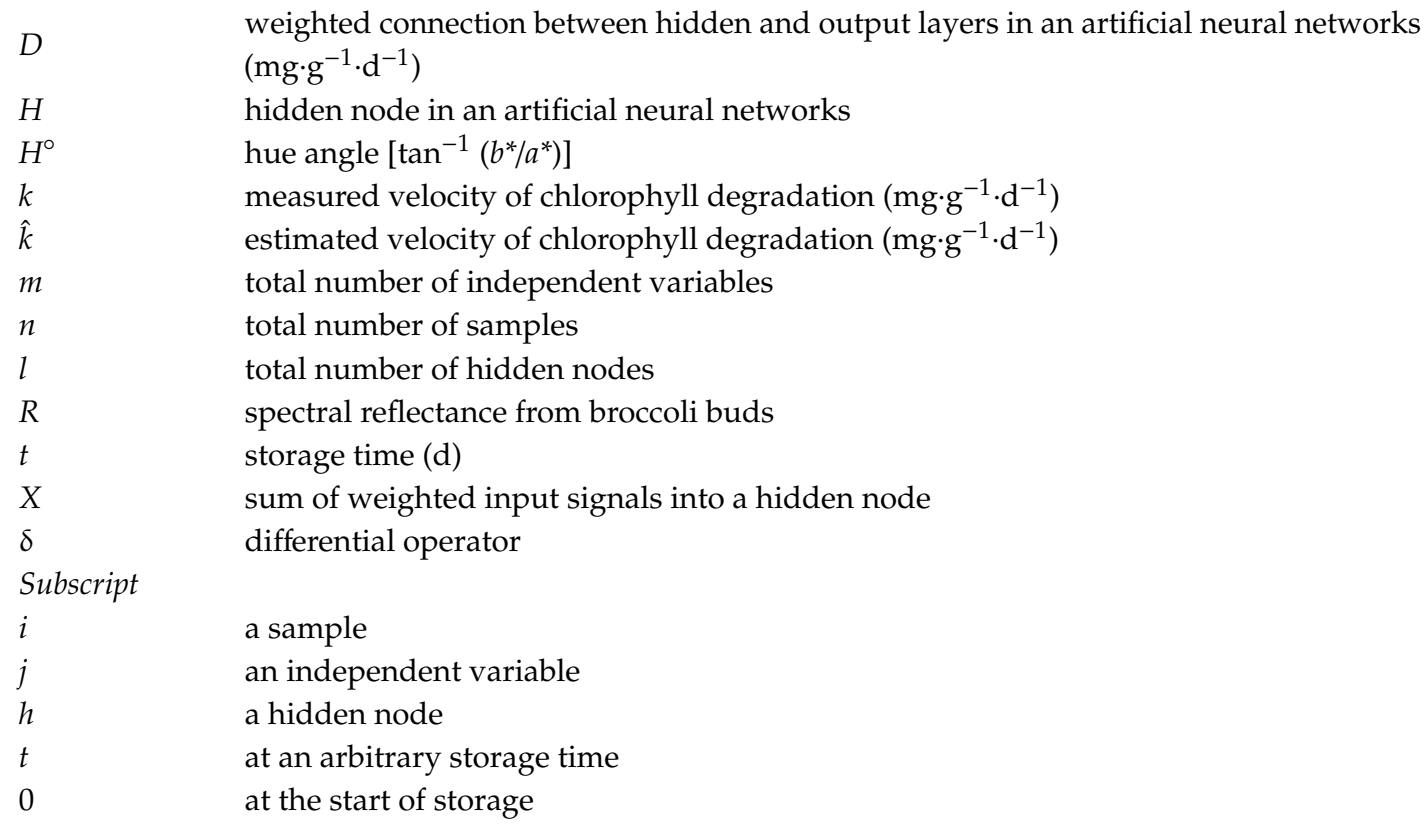

\section{References}

1. FAOSTAT. Available online: http://www.fao.org/faostat/en/\#home (accessed on 29 February 2020).

2. Nestle, M. Broccoli sprouts in cancer prevention. Nutr. Rev. 1998, 56, 127-130. [CrossRef] [PubMed]

3. Makino, Y.; Nishimura, Y.; Oshita, S.; Mizosoe, T.; Akihiro, T. Storage in high-barrier pouches increases the sulforaphane concentration in broccoli florets. PLoS ONE 2018, 13, e0192342. [CrossRef] [PubMed]

4. Makino, Y.; Hashizume, M.; Boerzhijin, S.; Akihiro, T.; Yamada, T.; Okazaki, K. Influence of cold or frozen storage on temporal changes in sulforaphane and objective taste values of broccoli (Brassica oleracea var. italica) florets. Environ. Control Biol. 2019, 57, 45-51. [CrossRef]

5. Zhang, Y.S.; Talalay, P.; Cho, C.G.; Posner, G.H. A major inducer of anticarcinogenic protective enzymes from broccoli-isolation and elucidation of structure. Proc. Nat. Acad. Sci. USA 1992, 89, 2399-2403. [CrossRef] [PubMed]

6. Shewfelt, R.L.; Heaton, E.K.; Batal, K.M. Nondestructive color measurement of fresh broccoli. J. Food Sci. 1984, 49, 1612-1613. [CrossRef]

7. Aiamla-or, S.; Shigyo, M.; Ito, S.; Yamauchi, N. Involvement of chloroplast peroxidase on chlorophyll degradation in postharvest broccoli florets and its control by UV-B treatment. Food Chem. 2014, 165, $224-231$. [CrossRef]

8. Altschul, V.R.; Smart, T.A. Einfluß von chlorophyll und von pyrrol auf das serumcholesterin von kaninchen. Arzneim. Forsch. 1961, 11, 762-763.

9. Yamashita, K.; Nohara, Y.; Kumagai, M.; Namiki, M. Effect of chlorophyll on plasma lipids in rats. J. Home Econ. Jpn. 1991, 42, 589-594.

10. Lipton, W.J.; Harris, C.M. Controlled atmosphere effects on the market quality of stored broccoli (Brassica oleracea L., Italica Group). J. Am. Soc. Hort. Sci. 1974, 99, 200-205.

11. Jacobsson, A.; Nielsen, T.; Sjoholm, I. Effects of type of packaging material on shelf-life of fresh broccoli by means of changes in weight, colour and texture. Eur. Food Res. Technol. 2004, 218, 157-163. [CrossRef]

12. Ren, K.; Tu, K.; Pan, L.Q.; Chen, Y.Y. Kinetic modelings of broccoli color changes during chilled storage. J. Food Process. Preserv. 2006, 30, 180-193. [CrossRef]

13. Kasim, R.; Kasim, M.U.; Erkal, S. The effect of packaging after 1-MCP treatment on color changes and chlorophyll degradation of broccoli (Brassica oleracea var. italica cv. Monopoly). J. Food Agric. Environ. 2007, 5, 48-51.

14. Treitz, P.M.; Howarth, P.J. Hyperspectral remote sensing for estimating biophysical parameters of forest ecosystems. Prog. Phys. Geogr. 1999, 23, 359-390. [CrossRef]

15. Park, B.; Lu, R. Hyperspectral Imaging Technology in Food and Agriculture; Springer Science + Business Media LLC: New York, NY, USA, 2015; pp. 3-403. 
16. Qin, J.W.; Burks, T.F.; Ritenour, M.A.; Bonn, W.G. Detection of citrus canker using hyperspectral reflectance imaging with spectral information divergence. J. Food Eng. 2009, 93, 183-191. [CrossRef]

17. Ariana, D.P.; Lu, R.F. Evaluation of internal defect and surface color of whole pickles using hyperspectral imaging. J. Food Eng. 2010, 96, 583-590. [CrossRef]

18. Ariana, D.P.; Lu, R.F. Hyperspectral waveband selection for internal defect detection of pickling cucumbers and whole pickles. Comput. Electron. Agric. 2010, 74, 137-144. [CrossRef]

19. Ahn, D.; Choi, J.Y.; Kim, H.C.; Cho, J.S.; Moon, K.D.; Park, T. Estimating the composition of food nutrients from hyperspectral signals based on deep neural networks. Sensors 2019, 19, 1560. [CrossRef]

20. Feng, C.H.; Makino, Y.; Yoshimura, M.; Rodríguez-Pulido, F.J. Estimation of adenosine triphosphate content in ready-to-eat sausages with different storage days using hyperspectral imaging coupled with $\mathrm{R}$ statistics. Food Chem. 2018, 264, 419-426. [CrossRef]

21. Goetz, A.F.H.; Vane, G.; Solomon, J.; Rock, B.N. Imaging spectrometry for earth remote sensing. Science 1985, 228, 1147-1153. [CrossRef]

22. Nicotra, A.B.; Hofmann, M.; Siebke, K.; Ball, M.C. Spatial patterning of pigmentation in evergreen leaves in response to freezing stress. Plant Cell Environ. 2003, 26, 1893-1904. [CrossRef]

23. Xue, L.; Yang, L. Deriving leaf chlorophyll content of green-leafy vegetables from hyperspectral reflectance. ISPRS J. Photogramm. Remote Sens. 2009, 64, 97-106. [CrossRef]

24. Kabakeris, T.; Poth, A.; Intress, J.; Schmidt, U.; Geyer, M. Detection of postharvest quality loss in broccoli by means of non-colorimetric reflection spectroscopy and hyperspectral imaging. Comput. Electron. Agric. 2015, 118, 322-331. [CrossRef]

25. Global Food Losses and Food Waste. Available online: http://www.fao.org/3/mb060e/mb060e.pdf (accessed on 29 February 2020).

26. Williams, P.; Norris, K. Chemical principles of near-infrared technology, Data analysis: Wavelength selection method, Neural networks in near-infrared spectroscopy, Implementation of near-infrared technology. In Near-Infrared Technology, 2nd ed.; American Association of Cereal Chemists, Inc.: St Paul, MN, USA, 2001; pp. 19-37, 39-58, 101-107, 145-169.

27. Marini, F. Artificial neural networks in foodstuff analyses: Trends and perspectives A review. Anal. Chim. Acta 2009, 635, 121-131. [CrossRef] [PubMed]

28. Makino, Y.; Isami, A.; Suhara, T.; Goto, K.; Oshita, S.; Kawagoe, Y.; Kuroki, S.; Purwanto, Y.A.; Ahmad, U. Nondestructive evaluation of anthocyanin concentration and soluble solid content at the vine and blossom ends of green mature mangoes during storage by hyperspectral spectroscopy. Food Sci. Technol. Res. 2015, 21, 59-65. [CrossRef]

29. Porra, R.J.; Thompson, W.A.; Kriedemann, P.E. Determination of accurate extinction coefficients and simultaneous equations for assaying chlorophylls a and $b$ extracted with four different solvents: Verification of the concentration of chlorophyll standards by atomic absorption spectroscopy. Biochim. Biophys. Acta 1989, 975, 384-394. [CrossRef]

30. Van Boekel, M.A.J.S. Kinetic modelling in food science: A case study on chlorophyll degradation in olives. J. Sci. Food Agric. 2000, 80, 3-9. [CrossRef]

31. Savitzky, A.; Golay, M.J.E. Smoothing and Differentiation of Data by Simplified Least Squares Procedures. Anal. Chem. 1964, 36, 1627-1639. [CrossRef]

32. Peiris, K.H.S.; Dull, G.G.; Leffler, R.G.; Kays, S.J. Near-infrared (NIR) spectrometric technique for nondestructive determination of soluble solids content in processing tomatoes. J. Am. Soc. Hortic. Sci. 1998, 123, 1089-1093. [CrossRef]

33. O'Neil, M.J. The Merck Index, 14th ed.; Merck \& Co. Inc.: Whitehouse Station, NJ, USA, 2006; pp. $356-357$.

34. Griffiths, D.E.; Wharton, D.C. Studies of the electron transport system. XXXV. Purification and properties of cytochrome oxidase. J. Biol. Chem. 1961, 236, 1850-1856.

35. Makino, Y.; Ichimura, M.; Kawagoe, Y.; Oshita, S. Cytochrome $c$ oxidase as a cause of variation in oxygen uptake rates among vegetables. J. Am. Soc. Hortic. Sci. 2007, 132, 239-245. [CrossRef]

36. Mester, P.; Wagner, M.; Rossmanith, P. Biased spectroscopic protein quantification in the presence of ionic liquids. Anal. Bioanal. Chem. 2010, 397, 1763-1766. [CrossRef] [PubMed]

37. Nicolai, B.M.; Beullens, K.; Bobelyn, E.; Peirs, A.; Saeys, W.; Theron, K.I.; Lammertyn, J. Nondestructive measurement of fruit and vegetable quality by means of NIR spectroscopy: A review. Postharvest Biol. Technol. 2007, 46, 99-118. [CrossRef] 
38. Makino, Y.; Ichimura, M.; Oshita, S.; Kawagoe, Y.; Yamanaka, H. Estimation of oxygen uptake rate of tomato (Lycopersicon esculentum Mill.) fruits by artificial neural networks modelled using near-infrared spectral absorbance and fruit mass. Food Chem. 2010, 121, 533-539. [CrossRef]

39. Siripatrawan, U.; Makino, Y.; Kawagoe, Y.; Oshita, S. Rapid detection of Escherichia coli contamination in packaged fresh spinach using hyperspectral imaging. Talanta 2011, 85, 276-281. [CrossRef] [PubMed] 